\title{
The Dog as a Risk Factor in Transmission of Visceral Leishmaniasis: A Review
}

\section{Francisco Assis Lima Costa}

Department of Clinical Veterinary Medicine and Surgery, Federal University of Piaui, Teresina, Brazil

Email: fassisle@gmail.com

Received April 1 ${ }^{\text {st }}, 2012$; revised May $5^{\text {th }}, 2012$; accepted Jun $1^{\text {st }}, 2012$

\begin{abstract}
Visceral leishmaniasis (VL) is a serious public health problem in Brazil and worldwide. Despite the euthanasia of dogs serologically positive, such action has not solved the endemic in Brazil. A risk area for VL involves the presence of the vector, the occurrence of canines and the record of human cases. The factors that have favored the persistence and spread of VL in Brazil are related to the predatory action of man on the environment, to the migratory movements and rural exodus, and a close coexistence of man and animals. Thus considering the epidemiological chain of VL, one fact seems clear: we do not know yet the true extent of the participation of the dog in the infectious cycle of VL. The clinical disease is an important indicator of the extent of the problem in an endemic area. The immunological events are complex and involve resistance and susceptibility to canine visceral leishmaniasis (CVL). One aspect in CVL is that many symptomatic dogs underwent xenodiagnosis not infect the vector. In such cases the pattern recognition receptors CD11b+, TLR2+, and NO present higher values for dogs with results in immunohistochemistry of skin and xenodiagnosis negative $\left(\mathrm{IMH}^{-} / \mathrm{XENO}^{-}\right)$than dogs with immunohistochemistry in skin and xenodiagnosis positive $\left(\mathrm{IMH}^{+} / \mathrm{XENO}^{+}\right)$, suggesting that innate immunity modulates the competence of the dog to infect the vector. The organic response in CVL varies from individual to individual and within the same individual, with a strong evidence of being organ-specific. Only $20 \%$ of asymptomatic dogs have parasites in the skin and $15 \%$ are able to recover from clinical signs and eliminate the parasites spontaneously. In this review, we analyze the epidemiology of visceral leishmaniasis and clinical, immunological and pathological conditions that can contribute to understanding the role of dogs in transmission of visceral leishmaniasis.
\end{abstract}

Keywords: Visceral Leishmaniasis; Dog; Epidemiology; Pathology

\section{Introduction}

Canine visceral leishmaniasis (CVL) is a systemic disease caused by Leishmania (Leishmania) chagasi $(\mathrm{Syn}=$ L. infantum) [1] on the American continent, with great impact on public health in Brazil because it is so endemic and $\operatorname{dog}$ is the most important reservoir of visceral leishmaniasis in urban and periurban areas [2,3]. About $90 \%$ of cases of VL in the Americas occurring in Brazil. Between 1990 and 2010, were notified by the Ministry of Health, 64.953 cases of human VL [4]. It is estimated that in each case human occur an average of at least 200 dogs previously infected $[5,6]$.

The vectors of visceral leishmaniasis are Phlebotomine females belonging to two main genera: Phlebotomus and Lutzomyia. Lutzomyia longipalpis is the vector of Leishmania (L.) chagasi in the Americas. Phlebotomus are vectors of species that cause visceral leishmaniasis in the Old World [7]. The biological cycle of Lutzomyia longipalpis includes four stages of development: egg, larva, pupa and adult, occurring over a period of approximately 30 to 40 days of the egg stage until the adult stage. The females have a longevity of 20 days and are obligatory hematophagous, feeding on various species of vertebrates [8]. The female infected while performing the blood meal in the vertebrate host, including man and the dog, release the infective forms (metacyclic stage) in the dermis of the host where they are phagocytosed by macrophages, differentiate into amastigotes and multiply intensely, being driven by hematogenous and/or lymphatic route to other tissues rich in cells of the mononuclear phagocytic system as lymph nodes, liver, spleen and bone marrow [9].

The infectious cycle of VL occurs in a wild environment and in an urban environment. In the sylvatic cycle, foxes and marsupials are considered major reservoirs, but in the urban cycle, domestic dogs are the main reservoir, assuming importance in the epidemiology of the human 
VL [10,11]. The main clinical manifestations of CVL consist of skin disease, enlargement of lymph nodes, eye disease, pallor of mucous membranes, enlarged spleen, cachexia, fever, nose bleeding (epistaxis), abnormal nails (onychogryposis) [12].

The CVL is considered more important than the human disease, because the dogs infected has high parasitic load on the skin, making them the main source of infection for the vectors [13]. However, despite the control measures adopted by the Ministry of Health, which has as its central action to eliminate serologically positive dogs for VL, they are not effective in solving the endemic in the country [14].

Thus, considering the various elements present in the epidemiological chain of visceral leishmaniasis, one fact seems clear: we do not know yet the true extent of the participation of the dog in the infectious cycle of the visceral leishmaniasis.

In this review we do an analysis of the epidemiology of visceral leishmaniasis and clinical, immunological and pathological conditions that can contribute to understanding the role of dogs in transmission of visceral leishmaniasis.

\section{Epidemiological Aspects}

Visceral leishmaniasis (VL) is endemic in Brazil and is expanding rapidly $[15,16]$. The factors that have favored the persistence and spread of the disease are related to the predatory action of man on the environment, to the conditions of environment and climate that favor the survival of the parasite and vector, to the migratory movements and rural exodus into large urban centers, associated with poor health conditions, and a close coexistence of man and animals [17,18].

In Northeastern Brazil, where $94 \%$ of cases are recorded, the disease has an endemic-epidemic behavior, with outbreaks being repeated approximately every 10 years [19]. This periodicity of the disease has been explained by both the accumulation of susceptible and by the occurrence, often cyclic, of natural disasters, such as drought (more frequent) and floods, which determine the worsening of socio-economic conditions of migrant populations [20].

The largest percentage of individuals who contract the disease are those of low income who live in rural areas and outskirts of urban centers, weakened by malnutrition, the poor housing conditions and sanitation, where the presence of wild animals in close relationship with man is common [21,22].

The delineation of a risk area for VL involves: 1) the presence of the vector (as an indicator of receptivity); 2) the occurrence of canines (as an indicator of potential risk) and 3) the record of human cases (as an indicator of an actual risk of transmission) [17].

Lutzomyia longipalpis is very adaptable to the periodmestic environment. The highest concentration of sandflies occurs between 18 h $(6$ p.m. $)$ and 22 h (10 p.m.) peridomestically and between $20 \mathrm{~h}(8 \mathrm{p} . \mathrm{m}$.) and $2 \mathrm{~h}(2$ a.m.) intradomestically. It is more common peridomestically than intradomestically $[23,24]$. The highest frequency rates are observed mainly in the rainy season $[25,26]$.

In Brazil, several mammals have been found to be infected by Leishmania (L.) chagasi, canids like the fox (Cerdocyon thous), the maned wolf (Chysocyon brachyurus), hoary zorro (Lycalopex vetulus) and bush dog (Spheotos venaticus), and other mammals such as the marsupial Didelphis albiventris and D. marsupialis, but only the fox (Cerdocyon thous), considered a natural reservoir of visceral leishmaniasis, appears to be important as a link in the enzootic cycle for maintenance of the disease [27-29].

In endemic areas such as Teresina city in Piaui, Brazil, Foxes (Cerdocyon thous) naturally infected by $L$. chagasi have been observed in dense residual forests, remnants of palm grove forests, near orchards and peridomestically on the outskirts of the city. These animals have presented high titers of antibodies protecting against the saliva of Lu. longipalpis, suggesting contact between the fox and the VL vector. Serum samples from humans and dogs living in the same area showed less reactivity against vector saliva when compared to fox saliva. These findings suggest that a natural focus of $L$. chagasi transmission exists, regardless of transmission between dogs and humans. It appears that transmission of VL infection to humans may partly originate from a sylvatic cycle and not depend solely on the presence of infected dogs [10].

The increased risk of humans contracting VL is related to malnutrition, to the presence of animals in homes, vegetation and vacant lots near homes, proximity to green areas (forests), poor conditions of urban infrastructure. These factors proved relevant in the context of epidemiological transmission of VL [30]. On the other hand, the presence of the dog appears to increase the risk of contracting VL, equivalent to 2.17 times compared with individuals who do not have dogs. This estimate becomes more worrying when we consider the number of dogs per residence. Residents with a dog in their homes have an increased risk of acquiring VL of 1.87 times, while the owners of two dogs increased the risk by 3.36 , compared to people who do not have dogs. The increaseing risk trend in the presence of dogs confirms the importance of this animal in the epidemiology of VL, either as an attractive source of food for the vector, or by its potential to serve as a reservoir of the parasite $[11,31]$. The association between human infection and the presence of dogs could also be verified by Vexenat et al. 
(1994) [32]. Another study found a relationship between high prevalence of canine infection and high incidence of human infection, associated with poor socio-economic conditions in the endemic area of the municipality of Teresina [14]. The responsible ownership of dogs is a problem in the communities of the suburbs of large urban centers, because the socio-economic difficulties do not allow the creation of the dogs properly. Other important aspects, intrinsic to the dog, which contribute to increase the risk of contracting VL, are related to the belated recognition of the disease, the low sensitivity of diagnostic tests and the delay between diagnosis and the euthanasia of positive dogs (average of 80 to 180 days) [17].

Although urbanization of VL has been in progress for over 25 years in Brazil, little is known about the determinants of urban transmission. In urban areas, social networks, population density, housing and the relationship with the natural environment are more varied and complex when compared to rural environments. Furthermore, environmental and climate changes coexist. Deforestation decreased the availability of animals serving as food sources for the sandfly vector in rural environments. Dogs and humans became more attainable alternatives. This may explain the invasion of Lu. Longipalpis in urban areas, increasing the transmission capacity of L. chagasi. On the other hand investments in health and education have been reduced, thus interrupting VL control and causing to adapt of the vector to an environment modified by man. Studies relating to the vector (genetic variants) are lacking. There are also new immunosuppressive factors, such as HIV infection. Disease control is difficult in large urban areas, where malnutrition, housing and sanitation problems are present [10].

However, these issues are complex, because not always the occurrence of the disease is associated with the presence of the dog, considered the main source of infection for human, and the systematic removal of these animals has not decreased the prevalence of human infection, and the indiscriminate euthanasia of dogs is a questionable procedure $[33,34]$. However a controlled intervention study conducted to determine whether the elimination of seropositive dogs would decrease the incidence and prevalence of visceral leishmaniasis in dogs and in humans, suggest that the elimination of the majority of seropositive dogs may affect the cumulative incidence of seroconversion in dogs temporarily and may also diminish the incidence of human cases of visceral leishmaniasis, although the transmission has continued after removal of the dogs which suggests the presence of other reservoirs [35]. The infectious cycle of visceral leishmaniasis is complex and establishes itself, among other elements, with the participation of the dog, which is the main domestic reservoir of the parasite $[7,8,35]$. Thus, one of three basic actions of the control program of vis- ceral leishmaniasis is centered on the massive elimination of dogs, usually based on results of serological tests, which have neither a high sensitivity nor high specificities, without the necessary parasitological confirmation.

Given that the control measures currently adopted has been successful, we suggest that such measures take into account a clinical evaluation of the disease more accurately as has been done in experimental studies [36,37], carry out identification and control of animals of the synanthropic fauna, adopt more appropriate sanitation, since areas with poor socioeconomic conditions, such as Teresina, the capital of the state of Piauí in Brazil, have been associated with an abundance of vectors in urban areas and incidence of canine and human VL [22]. Several studies on vaccination of dogs with leishmaniasis are being conducted, but results are inconsistent and treatment of dogs against visceral leishmaniasis is prohibited by federal law in Brazil (Portaria Interministerial $\mathrm{n}^{\circ}$ 1.426/2008, da Secretaria de Vigilância Sanitária, do Ministério da Saúde).

\section{Clinical Aspects}

In endemic areas, CVL is highly prevalent, affecting about $60 \%$ to $80 \%$ of the population of dogs, but it is accompanied by a low rate of clinical disease [38,39]. Thus, there are two populations of infected dogs: one that is clearly susceptible and another that is clearly resistant. These two populations respond clinically, immunologically and pathologically different to the infection with Leishmania (Leishmania) chagasi.

CVL is clinically classified as follows: asymptomatic dogs, consisting of animals serologically and parasitologically positive but no clinical signs suggestive of the disease; oligosymptomatic dogs, those who are serologically and parasitologically positive and have a maximum of three clinical signs of the disease whatever they are, and symptomatic or polissintomáticos dogs, those serologically and parasitologically positive with more than three characteristic clinical signs of the disease [40]. However, this classification is somewhat empirical, because it does not take into account the pathophysiological and immunological parameters of the infected dogs and therefore should be further defined.

The susceptible population presents a dynamic spectrum of manifestations ranging from sub clinical disease to a thoroughly manifest disease, accounting for onethird of infected animals [41]. After infection with Leishmania parasite persists throughout the life of the dog. The disease has an incubation period ranging from 3 months to 7 years $[36,37,42]$. After installation of clinical disease (symptomatic dogs) dogs can survive for months to years [36]. This population of dogs present the most frequent manifestations: onicogriphosis $(83.3 \%)$, skin 
lesions $(83.3 \%)$, conjunctivitis $(75 \%)$, local or generalized lymphadenopathy (66.6\%), and weight loss (58.3\%) [43]. On the other hand, $60 \%-80 \%$ of many animals that have contact with the parasite, as demonstrated by the presence of anti-Leishmania antibodies or specific immune response mediated by cell or by the detecting of the parasite DNA by the polymerase chain reaction, do not show any clinical manifestations of the disease $[37,38,44]$. An experimental study revealed that nine dogs of 21 infected remained healthy for a period of 5 years of follow-up [44]. However, case of immunosuppression such as disease can lead to activation of latent infection. In this context it is noteworthy that canine visceral leishmaniasis is very similar to human visceral leishmaniasis and reproduces clinical, immunological and pathological manifestations similar as weight loss, fever, anemia, diarrhea, hyperproteinemia with hypergammaglobulinemia, polyclonal activation of $\mathrm{B}$ cells, specific and nonspecific antibody production, culminating in the formation of high levels of anti-Leishmania antibodies and circulating immune complexes that are not protective, protective response conferred by $\mathrm{T}$ cells, splenomegaly, hepatomegaly, lymphadenopathy, glomerulonephritis [12].

The clinical examination is a rapid diagnosis, but for canine visceral leishmaniasis, is difficult to perform in endemic area, because the disease is similar to many others and the existence of a large number of asymptomatic and oligosymptomatic dogs are limitations to the application of this criterion [9]. On the other hand, has been observed that dogs showing clinical signs of onicogriphosis, skin lesions, conjunctivitis, local or generalized lymphadenopathy, and weight loss, should be considered for the diagnosis of canine VL. However, in a group of 35 dogs previously studied by us two from 16 animals presenting one or two symptoms were parasitologically negative. Therefore we suggest that only one or two of these symptoms are not sufficient, but three of them allow us to consider the animal as suspect, and five as strongly suggestive of VL [43].

Thus, it appears that clinical disease is an important indicator of the extent of the problem in an endemic area, because most dogs that are exposed and infected do not manifest the disease.

\section{Immunological Aspects}

The CVL is immunologically mediated and seems to develop according to the anergic model, inducing suppression of $\mathrm{T}$ cells, polyclonal activation of $\mathrm{B}$ cells, specific and nonspecific antibody production, culminating in the formation of high levels of anti-Leishmania antibodyies and circulating immune complexes $[42,46]$.

The immunological events related to the resistance and susceptibility to the CVL are not well defined, but they appear to be mediated by $\mathrm{T}$ cells [45,46-49]. Specific cellular immunity is observed in asymptomatic dogs naturally infected with Leishmania infantum [44,50]. A longitudinal experimental study on CVL has indicated a mixed Th1 and Th2 response in which the control of the replication of the parasite, progression of the disease or cure, is determined by the balance between these two dichotomous patterns [51]. On the other hand, some studies show that the protective response in dogs appears to be related to the cellular immunity associated with the activation of Th1 cells producing IFN- $\gamma$, IL-2, TNF- $\alpha$, and antigen-specific IgG-2. The macrophages activated by the Th1 (IFN- $\gamma)$ response present an increased production of reactive oxygen and nitrogen, via NADPH oxidase and nitric oxide synthase (iNOS), relating to the elimination of intracellular forms of Leishmania, as well as the activation of $\mathrm{CD} 8+\mathrm{T}$ cells that are also related to the resolution of the disease. These responses are reflected by the absence of clinical signs, by the low levels of anti-Leishmania antibodies, by the low parasite load and by the presence of a strong lymphoproliferative response or response to a delayed-type hypersensitivity (DTH) to Leishmania antigen in the skin [52-55]. The relationship between resistance to disease and cellular immunity was demonstrated by the inverse correlation between the percentage of $\mathrm{CD} 4 / \mathrm{TcR} \alpha \beta$ cells and the rate of infection of Phlebotomus perniciosus females [56]. The authors suggest that the percentage of $T$ helper cells present in peripheral blood of a dog should be considered a good parameter for evaluating the potential of infection for the vector, giving thus an idea of their epidemiological risk.

Furthermore, in an active disease the animals are incapable of developing an effective cellular immune response. In this case, a potent humoral response occurs, a specific immunosuppression against the parasite and the manifestation of a variety of clinical signs, whose severity is related to the parasite load in different organs and tissues $[52,57,58]$. The pattern of cytokines observed in this condition is a mixed Th1/Th2 response [53,59].

A study on the quantification of cytokine expression by real-time PCR (qRT-PCR) established that high levels of IFN- $\gamma$ are expressed by mononuclear cells from the peripheral blood of asymptomatic dogs after in vitro stimulation with Leishmania antigen, compared to polysymptomatic animals and uninfected control dogs. IFN- $\gamma$ has been shown to be a mediator of resistance to the parasites because of its ability to induce killing of the parasite by macrophages [60].

One aspect that draws attention in the course of the CVL is that many symptomatic dogs underwent xenodiagnosis not infect the vector. This fact seems to be due infection mediating by the innate immune system. In this 
sense, an experiment performed with peripheral blood of 48 naturally infected dogs revealed that the standard recognition receptors $\mathrm{CD} 11 \mathrm{~b}+$, TLR2+, and NO present higher values for dogs with results in immunohistochemistry of skin and xenodiagnosis negative $\left(\mathrm{IMH}^{-} /\right.$ $\mathrm{XENO}^{-}$) than dogs with immunohistochemistry in skin and xenodiagnosis positive $\left(\mathrm{IMH}^{+} / \mathrm{XENO}^{+}\right)$, suggesting that innate immunity is important in modulating the competence of the dog with VL to infect the vector [61].

\section{Pathological Aspects}

The pathology of CVL shows that resistant animals exhibit low parasite burden and reduced inflammatory response, making it difficult to find parasites in the skin and in organs of the mononuclear phagocyte system $[39,43]$. However, the organic response to parasite varies from individual to individual and the same individual showed evidence of being specific organ [62].

The dog's skin is the first organ to be infected by the vector and the presence of parasites gives the dog the condition of an important reservoir of Leishmania (Leishmania) chagasi, allowing easy transmission of the parasite to the vector $[33,63,64]$. This aspect has served as a justification for the indiscriminate euthanasia of dogs over the years, although the Organización Panamericana de la Salud and the Organización Mundial de la Salud recognize that animals are of great sentimental, economic, zootechnical and practical values, and therefore they should not be indiscriminately killed [17].

During the blood meal Lutzomyia longipalpis promastigotes inoculated into the skin of the host. The presence of the parasite causes changes in the epidermis characterized as acanthosis, hyperkeratosis and a dermal inflammatory reaction predominantly histiolymphoplasmocytic diffuse or focal periadnexal, perivascular, and granulomatous [65-67]. There is a correlation between the intensity of the inflammatory infiltrate and the parasite load. Have been observed that when few parasites are present, the inflammatory infiltrate consists mainly of lymphocytes and macrophages, but in the presence of many parasites in the dermis, the infiltrate is also comprised of lymphocytes and monomorphic macrophages, as well as a larger quantity of polymorphonuclear neutrophils (PMNs) [43]. The parasite load, measured by immunohistochemistry, is higher in the ear and ungueal region $[43,68]$. The sensitivity of PCR is higher $(82.76 \%)$ than immunohistochemistry $(62.07 \%)$ and than $\mathrm{H}-\mathrm{E}$ $(44.83 \%)$ to detect the parasite [65].

Histochemical techniques revealed that animals with an intense inflammatory infiltrate in the skin, show a predominance of type III collagen (reticular fibers) and a lesser proportion of type I collagen (connective tissue proper), revealing profound structural changes in colla- genous components of the extracellular matrix of the skin [69]. It is likely that the leishmania use the collagen fibers to evade the immune response and migrate to other organs of the host [70,71]. The assessment of the epidermal immunocompetence in canine visceral leishmaniasis showed that in cases of alopecia dermatitis, Langerhans cells and positive keratinocytes for MHC II are associated with $\mathrm{T}$ cell infiltration of medium intensity, without significant numbers of parasites. On the contrary, in the absence of antigen-presenting cells in the epidermis, as observed in nodular lesions, an intense infiltrate of macrophages and parasites in the dermis occurs. Ulcerative lesions show an intermediate pattern of inflamemation. These results suggest that dogs with alopecia dermatitis develop an effective control of the infection [72]. The alteration of the extracellular skin matrix is higher in symptomatic than in asymptomatic dogs. Fibronectin and laminin are present in greater intensity in symptomatic than in asymptomatic dogs [73].

While about $60 \%$ to $80 \%$ of all dogs with amastigotes do not show any clinical signs of disease, only $20 \%$ of these animals have parasites in the skin and $15 \%$ are able to recover from clinical signs and eliminate the parasites spontaneously $[51,74]$. Thus, in the scope of the epidemiology of VL, the parasites of the skin and hence the ability to infect the vector, has been the subject of intense research in recent years, but the results of these studies are still conflicting. In Ceará state, Brazil, among asymptomatic dogs, only $8 \%$ with amastigotes in the skin were found by molecular method while in Piaui state over $30 \%$ were parasitized $[31,75]$. A report of the histological picture in tissues of a naturally-infected asymptomatic dog showed marked inflammatory changes and the presence of many amastigotes in ear, nose and abdomen [65].

A study by xenodiagnosis showed that dogs with clinical manifestations for VL were four times more infective to the vector than oligosymptomatic and asymptomatic dogs. Leishmania DNA was detected in $100 \%$ of skin samples from symptomatic and oligosymptomatic dogs and to a lesser extent $(66.7 \%)$ in asymptomatic dogs. The rate of infectivity was determined as $33.3 \%(2 / 6)$, $16.7 \%(1 / 6)$ and $83.3 \%(5 / 6)$ for asymptomatic, oligosymptomatic and symptomatic dogs, respectively [76]. It should be noted that the correlation between the presence of symptoms and infectivity to the vector varies in different geographic regions. It is likely that this variation is influenced by the number of infected animals and vectors in a particular region, as well as the vector competence to transmit the infection. The severity of the disease is manifested by the clinical condition of the dog and this depends on the host-parasite interactions that differ between regions, because the environmental conditions are different. Even symptomatic dogs present levels of infec- 
tivity for different vector, which is dependent on the immune status of the animal, with a relevant role for innate immunity [61]. A study in Spain showed no correlation, while in Colombia and in Brazil, a positive correlation between the presence of symptoms and infectivity to the vector has been shown $[64,77,78]$.

The spleen of naturally infected dogs by $L$. chagasi exhibit several markers of susceptibility to visceral leishmaniasis, including active parasitism, higher frequencies of generalized white pulp atrophy, an absence of germinal centers and a lack of definition of white pulp compartments associated with splenic architecture disruption, which is characterized by disorganization of normal lymphoid tissue, loss of normal spleen leucocyte diversity via replacement of leucocytes by plasma cells, and eventual atrophy of the lymphoid tissue [79]. In this sense it has been observed that the highest parasitism in spleen of infected dogs is associated with an increased expression of complement receptor 3 (CR3), indicating a possible role of CR3 positive cells in the maintenance of tissue parasitism [80]. A study in progress conducted by our group, have revealed that the clinical manifestations of CVL progress with the intensity of the changes in spleen including a higher number of granulomas and Russell bodies in dogs with two, three, four, and five symptoms compared to the dogs with only one symptom and the asymptomatic dogs (F. A. L. Costa: Unpublished Data). Research on the architecture of the spleen in dogs with VL has revealed that both the frequency of clinical manifestations and the densities of CD79a+ B lymphocytes and proliferating $(\mathrm{Ki}-67+)$ cells, the average numbers of CD79a+ B cells, T cells, S100+ DCs and proliferating cells were lower in dogs with disorganized splenic lymphoid tissue than in those of dogs with organized splenic tissue. These changes were associated with reduced expression of the cytokine CXCL13 that participates in the organization of lymphoid follicles through migration of B cell to the follicles [81]. These splenic markers may be important in the identification of dogs that represent the greatest risk of transmission of VL.

The lesion in the liver contribute to various clinicopathological changes, such as hypoalbuminemia, increased levels of transaminases (ALT, AST) and total protein [55], but rarely reaches the stage of liver failure [82]. The characteristic resistance of the liver in Leishmania infection is quite complex and it is known that the interaction between the Kupffer cells and CD8+ $\mathrm{T}$ cells within granulomas has important implications for the identification of novel antigens vaccine candidates that may serve as new model of immuno-therapeutic intervention [83]. The liver show a greater number of intralobular granulomas in asymptomatic compared to symptomatic animals [51]. Hyperplasia and hypertrophy of Kupffer cells and granulomas are changes with a high incidence. Injuries such as congestion of the sinusoidal capillaries, inflammatory cells in the portal space and in the capsule, and degeneration are present in a varying degree. Positive hepatic cells for the expression of CR3 are associated with a lower tissue parasitism, suggesting that these cells in liver have a protective role in the immune response in CVL [80].

In lymph nodes, it can be observed a thickening of the capsule due to the infiltration of mononuclear cells, mainly macrophages, follicular hyperplasia, hyperplasia and hypertrophy of cells of the sinus and medullary cords, with amastigotes within macrophages [81]. These changes are often responsible for the enlargement of the lymph node [84] with a humoral and cellular immune response related to the evolution of the infection [52]. There are few studies showing cell profiles in lymph nodes of dogs with VL, but the main change immuno- phenotypic is an increased frequency of $\mathrm{T}$ lymphocytes, particularly CD8+ $\mathrm{T}$ cells, an increased expression of MCH-II by lymphocytes and a decrease in the levels of $\mathrm{CD} 21+\mathrm{B}$ cells. In a study in progress we have observed that depletion of follicles and of cells of the paracortical area are more evident changes in symptomatic than in asymptomatic dogs, and hyperplasia of follicles is higher in asymptomatic dogs. The cell hyperplasia of the me- dullary sinus is higher in symptomatic when compared with the asymptomatic dogs (F. A. L. Costa: Unpub- lished Data). The popliteal lymph node is an organ easily accessible and thus can help to identify cell populations in dogs that represent an increased risk of transmission of VL. Studies conducted by our group showed that among symptomatic dogs xenodiagnosis was positive only when lymphadenopathy and/or splenomegly were present. These conditions were probably due to a higher level of parasitemia in the skin which facilitated the transmission to the insect [43].

The kidney is an organ often affected in the course of CVL. We conducted a study with 55 naturally infected dogs and verified the presence of glomerulonephritis in $100 \%$ and interstitial nephritis in $78.2 \%$, both in symptomatic and asymptomatic dogs. The changes were related to the presence of Leishmania antigen. Biochemical analyzes performed on serum and urine of $11 \mathrm{dogs}$ showed changes in renal function in six dogs. These changes were observed only in dogs who had concomitant interstitial nephritis and glomerulonephritis [85]. Renal involvement in canine visceral leishmaniasis is considered a frequent cause of death of animals [86]. Dogs with severe renal impairment are those with the disease in its full form, so are those with greater power to infect the vector. The kidney responds to infection with activation of humoral and cellular immune system and is not related to resistance and susceptibility to disease, as 
observed in the systemic response, but rather with the mechanism of renal injury, as observable in the nephropathy in general [87-90].

Furthermore, it has been suggested that a genetic predisposition to susceptibility and resistance to CVL occurs [12]. Two genes have been implicated in susceptibility to CanL: DLA (dog leukocyte antigen)-RB1*01502 allele in dogs in Brazil [91] and haplotypes of canine Slc11al gene in Spain [92].

Thus, the dog is a risk factor for transmission of VL because it presents high susceptibility, constituting the main reservoir of the parasite. Moreover, the close relationship between man and dog living in the same space, the intense parasitism of the dog's skin, the difficulty of clinical diagnosis, the similarity with other diseases, and the existence of asymptomatic dogs, give the dog this condition.

\section{Final Thoughts}

The dog represents an important link in the infectious cycle of VL. The parasitism of the skin allows the transmission of infection in the presence of the vector. However the dog response against the infection varies of animal to animal and between groups of animals that present variable susceptibility to the disease. Thus, it is right to devote priority attention to the dog, especially in endemic areas for VL. However, besides the dog there are many other elements involved in the infectious cycle of the disease, such as wild animals, animals of the synanthropic fauna, poor sanitation, which contribute to the advancement of the disease, as is happening in Brazil and around the world where the disease is present. The priority attention to the dog should take into account the peculiarities of the populations of dogs exposed to the infected vector and the different responses of the dog to the infection, to avoid an indiscriminate and inhumane action of elimination of dogs. Every day, many dogs that are not involved in the transmission of $\mathrm{VL}$ are euthanized. It needs to be taken into account that many infected animals do not pose a risk or pose a low epidemiological risk in the transmission of the infection because the skin does not present parasites. An aspect of the relationship between canine and human infection should be examined: Why in endemic areas for VL, which also have high rates of infection in dogs, few people are infected in absolute numbers? Those who fall ill, are usually the poor, marginalized on the peripheries of urban centers, where conditions of poor sanitation, a key factor in the spread of disease, determine precarious living conditions that attacks citizenship of these populations. Thus, the program to control the disease in Brazil, coordinated by the Ministry of Health, should encourage the development of new methods of work and research, which characterize better dogs that represent a real risk of transmission, that are consistent with the expectation of society that, in most cases, refuse to surrender their animals to be euthanized.

\section{REFERENCES}

[1] I. L. Maurício, J. R. Stothard and M. A. Miles, "The Strange Case of Leishmania chagasi," Parasitology Today, Vol. 16, No. 5, 2000, pp. 188-189. doi:10.1016/S0169-4758(00)01637-9

[2] R. Rethinger and C. R. Davies, "Is the Domestic Dog (Canis familiaris) a Reservoir Host of American Cutaneuos Leishmaniasis? A Critival Review of the Current Evidence," The American Journal of Tropical Medicine and Hygiene, Vol. 61, No. 4, 1999, pp. 530-541.

[3] C. B. Palatnik-de-Sousa, W. R. dos Santos, J. C. França-Silva, R. T. da Costa, A. B. Reis, M. Palatnik, W. Mayrink and O. Genaro, "Impact of Canine Control on the Epidemiology of Canine and Human Visceral Leishmaniasis in Brazil," The American Journal of Tropi -cal Medicine and Hygiene, Vol. 65, No. 5, 2001, pp. 510 -517.

[4] Sinan/SVS/MS, "Casos Confirmados de Leishmaniose Visceral, Brasil, Grandes Regiões e Unidades Federadas. 1990 a 2010,"

http://portal.saude.gov.br/portal/arquivos/pdf/lv_casos_05 09_11.pdf

[5] P. S. Monteiro, M. M. Lacerda and J. R. Arias, "Controle da Leishmaniose no Brasil," Revista da Sociedade Brasileira de Medicina Tropical, Vol. 27, Suppl. 3, 1994, pp. 67-72.

[6] P. Desjeux, "Leishmaniasis," Annals of Tropical Medicine and Parasitology, Vol. 97, Suppl. 1, 2003, pp. 3-15. doi:10.1179/000349803225002499

[7] R. Laison, "Ecology and Epidemiology: New World," In: W. Peters and R. Kiick-Kendrick, Eds., The Leishmaniasis in Biology and Medicine, Academic Press, London, 1987, pp. 291-363.

[8] Ministério da Saúde, "Manual de Vigilância e Controle da Leishmaniose Visceral," Secretaria de Vigilância em Saúde, Departamento de Vigilância Epidemiológica, Brasil, 2006.

[9] Ministério da Saúde, "Manual de Vigilância e Controle da Leishmaniose Visceral," Ministério da Saúde, Brasília, 2006.

[10] K. O. Drumond and F. A. L. Costa, "Forty Years of Visceral Leishmaniasis in the State of Piaui: A Review," Revista do Instituto de Medicina Tropical de Sao Paulo, Vol. 53, No. 1, 2011, pp. 3-11. doi:10.1590/S0036-46652011000100002

[11] C. Di Lorenzo and R. M. Assuncão, "A Urbanização da Leishmaniose Visceral no Brasil-Uma Breve Revisão," Revista da Sociedade Brasileira de Medicina Tropical, Vol. 33, Suppl. 1, 2000, pp. 316-317.

[12] G. Baneth, A. F. Koutinas, L. Solano-Gallego, P. Bourdeau and L. Ferrer, "Canine Leishmaniosis-New Concepts and Insights on an Expanding Zoonosis: Part One," Trends in Parasitology, Vol. 24, No. 7, 2008, pp. 324-330. 
doi:10.1016/j.pt.2008.04.001

[13] M. C. A. Marzochi, S. G. Coutinho, P. C. Sabroza, M. A. Souz, P. P. Souza, L. M. Toledo and F. B. Rangel Filho, "Leishmaniose Visceral Canina no Rio de Janeiro Brasil," Cadernos de Saúde Pública, Vol. 1, No. 4, 1985, pp. 432-446. doi:10.1590/S0102-311X1985000400004

[14] R. Dietze, L. Teixeira, J. Harris, K. Michelson, A. Falqueto and R. Corey, "Effect of Eliminating Seropositive Canines on the Transmission of viSceral Leishmaniasis in Brazil," Clinical Infectious Diseases, Vol. 25, No.5, 1997, pp. 1240-1242. doi:10.1086/516096

[15] T. G. Evans, I. A. Vasconcelos, J. W. Lima, J. M. Teixeira, I. T. McAullife, U. G. Lopes, R. D. Pearson and A. W. Vasconcelos, "Canine Visceral Leishmaniasis in Northeast Brazil: Assessment of Serodiagnostic Methods," American Journal of Tropical Medicine and Hygiene, Vol. 42, No. 2, 1990, pp.118-123.

[16] M. M. Feitosa, M. C. R. Luvizotto and S. H. V. Perri, "Aspectos Clínicos de Cães com Leishmaniose Visceral no Município de Araçatuba-São Paulo (Brasil)," Clínica Veterinária, Vol. 8, No. 28, 2000, pp. 36-44.

[17] Organización Panamericana de la Salud, Mnisterio de Salud de Brasil, Centro Panamericano de Fiebre Aftosa and Unidad de Salud Pública Veterinária, "Consulta de Expertos OPS/OMS sobre Leishmaniasis Visceral en las Américas," Brasilia, 23 al 25 de noviembre 2005.

[18] L. M. Deane, "Observações sobre a Transmissão da Leishmaniose Visceral no Ceará," O Hospital, Vol. 48, No. 3, 1955, pp. 347-364.

[19] Z. M. P. da Luz, D. N. Pimenta, A. L. L. V. Cabral, V. O. P. Fiúza and A. Rabello, "Leishmaniasis Urbanization and Low Diagnosis Capacity in the Metropolitan Region of Belo Horizonte," Revista da Sociedade Brasileira de Medicina Tropical, Vol. 34, No. 3, 2001, pp. 249-254.

[20] Fundação Municipal de Saúde, Departamento de epidemiologia, "Relatórios Técnicos Anuais, Teresina, Piauí," São Paulo, 2004.

[21] P. M. Wijeyaratne, L. K. Arsenault and C. J. Murphy, "Endemic Disease and Development: The Leishmaniases," Acta Tropica, Vol. 56, No. 4, 1994, pp. 349-364. doi:10.1016/0001-706X(94)90106-6

[22] G. L. Werneck, C. H. Costa , A. M. Walker, J. R. David, M. Wand and J. H. Maguire, "Multilevel Modelling of the Incidence of Visceral Leishmaniasis in Teresina, Brazil," Epidemiology and Infection, Vol. 135, No. 2, 2007, pp. 195-201. doi:10.1017/S0950268806006881

[23] R. A. Barata, J. C. França-Silva, W. Mayrink, J. C. Silva, A. Prata, E. S. Lorosa, J. A. Fiúza, C. M. Gonçalves, K. M. Paula and E. S. Dias, "Aspectos da Ecologia e do Comportamento de Flebotomíneos em Área Endêmica de Leishmaniose Visceral, Minas Gerais," Revista da Sociedade Brasileira de Medicina Tropical, Vol. 38, No. 5, 2005, pp. 421-425.

[24] N. A. Missawa, E. S. Lorosa and E. S. Dias, "Preferência Alimentar de Lutzomyia longipalpis (Lutz \& Neiva, 1912) em área de Transmissão de Leishmaniose Visceral em Mato Grosso," Revista da Sociedade Brasileira de Medicina Tropical, Vol. 41, No. 4, 2008, pp. 65-68.

[25] A. G. Oliveira, E. A. Galati, C. E. Fernandes, M. E. Dor- val and R. P. Brazil, "Seasonal Variation of Lutzomyia longipalpis (Lutz \& Neiva, 1912) (Diptera: Psychodidae: Phlebotominae) in Endemic Area of Visceral Leishmaniasis, Campo Grande, State of Mato Grosso do Sul, Brazil," Acta Tropica, Vol. 1052, No. 1, 2008, pp. 55-61. doi:10.1016/j.actatropica.2007.09.008

[26] J. M. M. Rebêlo, "Freqüência Horária e Sazonalidade de Lutzomyia longipalpis (Diptera: Psychodidae: Phlebotominae) na Ilha de São Luís, Maranhão, Brasil," Cadernos de Saúde Pública, Vol. 17, No. 1, 2001, pp. 221-227.

[27] N. H. A. Curi, I. Miranda and S. A. Talamoni, "Serologic Evidence of Leishmania Infection in Free-Ranging Wild and Domestic Canids around a Brazilian National Park," Memórias do Instituto Oswaldo Cruz, Vol. 101, No. 1, 2006, pp. 99-101. doi:10.1590/S0074-02762006000100019

[28] F. B. Figueiredo, I. D. Gremião, S. A. Pereira, L. P. Fedulo, R. C. Menezes, D. A. Balthazar, T. M. Schubach and M. F. Madeira, "First Report of Natural Infection of a Bush Dog (Speothos Venaticus) with Leishmania (Leishmania) chagasi in Brazil," Transactions of the Royal Society of Tropical Medicine and Hygiene, Vol. 102, No. 2, 2008, pp. 200-201. doi:10.1016/j.trstmh.2007.10.001

[29] H. D. Schallig, E. S. da Silva, W. F. van der Meide, G. J. Schoone and C. M. Gontijo, "Didelphis Marsupialis (Common Opossum): A Potential Reservoir Host for Zoonotic Leishmaniasis in the Metropolitan Region of Belo Horizonte (Minas Gerais, Brazil)," Vector Borne Zoonotic Disease, Vol. 7, No. 3, 2007, pp. 387-393. doi:10.1089/vbz.2006.0651

[30] B. K. A. Borges, J. A. Silva, J. P. A. Haddad, E. C. Moreira, D. F. Magalhães, L. M. L. Ribeiro and V. O. P. Fiúza, "Presença de Animais Associada ao Risco de Transmissão da Leishmaniose Visceral em Humanos em Belo Horizonte, Minas Gerais," Arquivos Brasileiros de Medicina Veterinária e Zootecnia, Vol. 61, No. 5, 2009, pp. 1035-1043. doi:10.1590/S0102-09352009000500004

[31] S. S. Oliveira and T. M. Araújo, "Avaliação das Ações de Controle da Leishmaniose Visceral (calazar) em Uma Área Endêmica do Estado da Bahia, Brasil (1995-2000)," Cadernos de Saúde Pública, Vol. 19, No. 6, 2003, pp. 1681-1690. doi:10.1590/S0102-09352009000500004

[32] J. A. Vexenat, J. A. Fonseca de Castro, R. Cavalcante, J. P. Tavares, M. R. B. da Silva, W. H. Batista, J. H. Furtado Campos, M. K. Howard, I. Frame, R. McNerney, S. Wilson and M. A. Miles, "Visceral Leishmaniasis in Teresina, State of Piaui, Brazil: Preliminary Observations on the Detection and Transmissibility of Canine and Sandfly Infections," Memórias do Instituto Oswaldo Cruz, Vol. 89, No. 2, 1994, pp. 131-135. doi:10.1590/S0074-02761994000200001

[33] R. Dietze, G. B. Barros, L. Teixeira, J. Harris, K. Michelson, A. Falqueto and R. Corey, "Effect of Eliminating Seropositive Canines on the Transmission of Visceral Leishmaniasis in Brazil," Clinical Infectious Diseases, Vol. 25, No. 5, 1997, pp. 1240-1242. doi:10.1086/516096

[34] T. G. Evans, M. J. Teixeira, I. T. McAuliffe, I. Vasconcelos, A. W. Vasconcelos, A. Sousa Ade, J. W. Lima and R. D. Pearson, "Epidemiology of Visceral Leishmaniasis in Northeast Brazil," The Journal of Infectious Diseases, 
Vol. 166, No. 5, 1992, pp. 1124-1132. doi:10.1093/infdis/166.5.1124

[35] D. A. Ashford, J. R. David, M. Freire, R. David, I. Sherlock, M. C. Eulálio, D. P. Sampaio and R. Badaro, "Studies on Control of Visceral Leishmaniasis: Impact of Dog Control on Canine and Human Visceral Leishmaniasis in Jacobina, Bahia, Brazil," The American Journal of Tropical Medicine and Hygiene, Vol. 59, No. 1, 1998, pp. 53-57.

[36] G. Oliva, A. Scalone, V. F. Manzillo, M. Gramiccia, A. Pagano, T. Di Muccio and L. Gradoni, "Incidence and Time Course of Leishmania infantum Infections Examined by Parasitological, Serologic, and Nested-PCR Techniques in a Cohort of Naïve Dogs Exposed to Three Consecutive Transmission Seasons," Journal of Clinical Microbiology, Vol. 44, No. 4, 2006, pp. 1318-1322. doi:10.1128/JCM.44.4.1318-1322.2006

[37] P. Paradies, M. Sasanelli, D. Caprariis, G. Testini, D. Traversa, R. P. Lia, F. Dantas-Torres and D. Otranto, "Clinical and Laboratory Monitoring of Dogs Naturally Infected by Leishmania infantum," The Veterinary Journal, Vol. 186, No. 3, 2010, pp. 370-373. doi:10.1016/j.tvj1.2009.09.011

[38] F. Berrahal, C. Mary, M. Roze, A. Berenger, K. Escoffier, D. Lamouroux and S. Dunan, "Canine Leishmaniasis: Identification of Asymptomatic Carriers by Polymerase Chain Reaction and Immunoblotting," The American Journal of Tropical Medicine and Hygiene, Vol. 55, No. 3, 1996, pp. 273-277.

[39] L. Solano-Gallego, P. Morell, M. Arboix, J. Alberola and L. Ferrer, "Prevalence of Leishmania infantum Infection in Dogs Living in an Area of Canine Leishmaniasis Endemicity Using PCR on Several Tissues and Serology," Journal of Clinical Microbiology, Vol. 39, No. 2, 2001, pp. 560-563. doi:10.1128/JCM.39.2.560-563.2001

[40] F. Mancianti, M. Gramiccia, L. Gradoni and S. Pieri, "Studies on Canine Leishmaniasis Control. 1. Evolution of Infection of Different Clinical Forms of Canine Leishmaniasis Following Antimonial Treatment," Transactions of the Royal Society of Tropical Medicine and Hygiene, Vol. 82, No. 4, 1988, pp. 566-567. doi:10.1016/0035-9203(88)90510-X

[41] R. Fisa, M. Gállego, S. Castillejo, M. J. Aisa, T. Serra, C. Riera, J. Carrió, J. Gállego and M. Portús, "Epidemiology of Canine Leishmaniosis in Catalonia (Spain) the Example of the Priorat Focus," Veterinary Parasitology, Vol. 83, No. 2, 1999, pp. 87-97. doi:10.1016/S0304-4017(99)00074-6

[42] R. J. Slappendel, "Canine Leishmaniasis. A Review based on 95 Cases in The Netherlands," The Veterinary Quarterly, Vol. 10, No. 1, 1988, pp. 1-16. doi:10.1080/01652176.1988.9694140

[43] B. L. Verçosa, C. M. Lemos, I. L. Mendonça, S. M. Silva, S. M. de Carvalho, H. Goto and F. A. Costa, "Transmission Potential, Skin Inflammatory Response, and Parasitism of Symptomatic and Asymptomatic Dogs with Visceral Leishmaniasis," BMC Veterinary Research, Vol. 4, No. 45, 2008, pp. 1-7. http://www.biomedcentral.com/1746-6148/4/45.
[44] M. Cabral, J. E. O'Grady, S. Gomes, J. C. Sousa, H. Thompson and J. Alexander, "The Immunology of Canine Leishmaniosis: Strong Evidence for a Developing Disease Spectrum from Asymptomatic Dogs," Veterinary Parasitology, Vol. 76, No. 3, 1998, pp. 173-180. doi:10.1016/S0304-4017(97)00208-2

[45] R. Killick-Kendrick, M. Killick-Kendrick, E. Pinelli, G. Del Real, R. Molina, M. M. Vitutia, M. C. Cañavate and J. Nieto, "A Laboratory Model of CANINE leishmaniasis: The Inoculation of Dogs with Leishmania infantum Promastigotes from Midguts of Experimentally Infected Phlebotomine Sandflies," Parasite, Vol. 1, No. 4, 1994, pp. 311-381.

[46] P. Abranches, C. L. Santos and G. M. Gomes, "Canine Leishmaniasis: New Concepts in Epidemiology and Immunology and Their Reflections in the Control of Human Visceral Leishmaniasis," Acta Médica Portuguesa, Vol. 11, No. 10, 1998, pp. 871-875.

[47] M. Cabral, J. O'Grady and J. Alexander, "Demonstration of Leishmania Specific Cell Mediated and Humoral Immunity in Asymptomatic Dogs," Parasite Immunology, Vol. 14, No. 5, 1992, pp. 531-539. doi:10.1111/j.1365-3024.1992.tb00026.x

[48] A. A. Binhazim, W. L. Chapman Jr., S. S. Shin and W. L. Hanson, "Determination of Virulence and Pathogenesis of a Canine Strain of Leishmania Leishmania infantum in Hamsters and Dogs," American Journal of Veterinary Research, Vol. 54, No. 1, 1993, pp. 113-121.

[49] A. Rhalem, H. Sahibi, N. Guessous-Idrissi, S. Lasri, A. Natami, M. Riyad and B. Berrag, "Immune Response against Leishmania Antigens in Dogs Naturally and Experimentally Infected with Leishmania infantum," Veterinary Parasitology, Vol. 81, No. 3, 1999, pp. 173-184. doi:10.1016/S0304-4017(98)00240-4

[50] M. Cabral, R. McNerney, S. Gomes, J. O'Grady, I. Frame, J. C. Sousa, M. A. Miles and J. Alexander, "Demonstration of Natural Leishmania Infection in Asymptomatic Dogs in the Absence of Specific Humoral Immunity," Archives de l'Institut Pasteur de Tunis, Vol. 70, No. 3-4, 1993, pp. 473-479.

[51] G. Baneth, A. F. Koutinas, L. Solano-Gallego, P. Bourdeau and L. Ferrer, "Canine Leishmaniosis-New Concepts and Insights on an Expanding Zoonosis: Part One," Trends in Parasitology, Vol. 24, No. 7, 2008, pp. 324330.

[52] E. Pinelli, R. Killick-Kendrick, J. Wagenaar, W. Bernadina, G. del Real and J. Ruitenberg, "Cellular and Humoral Immune Responses in Dogs Experimentally and Naturally Infected with Leishmania infantum," Infection and Immunity, Vol. 62, No. 1, 1994, pp. 229-235.

[53] E. Pinelli, S. Y. van der Kaaij, R. Slappendel, C. Fragio, E. J. Ruitenberg, W. Bernadina and V. P. Rutten, "Detection of Canine Cytokine Gene Expression by Reverse Transcription-Polymerase Chain Reaction," Veterinary Immunology and Immunopathology, Vol. 69, No. 2-4, 1999, pp. 121-126. doi:10.1016/S0165-2427(99)00048-3

[54] P. Holzmuller, R. Bras-Goncalves and J. L. Lemesre, "Phenotypical Characteristics, Biochemical Pathways, 
Molecular Targets and Putative Role of Nitric OxideMediated Programmed Cell Death in Leishmania," Parasitology, Vol. 132, 2006, pp. S19- S32. doi:10.1017/S0031182006000837

[55] A. B. Reis, A. Teixeira-Carvalho, A. M. Vale, M. J. Marques, R. C. Giunchetti, W. Mayrink, L. L. Guerra, R. A. Andrade, R. Corrêa-Oliveira and O. A. Martins-Filho, "Isotype Patterns of Immunoglobulins: Hallmarks for Clinical Status and Tissue Parasite Density in Brazilian Dogs Naturally Infected by Leishmania (Leishmania) chagasi," Veterinary Immunology and Immunopathology, Vol. 112, No. 3-4, 2006, pp. 102-116. doi:10.1016/j.vetimm.2006.02.001

[56] J. L. Guarga, J. Moreno, J. Lucientes, M. J. Gracia, M. A. Peribáñez, J. Alvar and J. A. Castillo, "Canine Leishmaniasis Transmission: Higher Infectivity Amongst Naturally Infected Dogs to Sand Flies Is Associated with Lower Proportions of T Helper Cells," Research in Veterinary Science, Vol. 69, No. 3, 2000, pp. 249-253. doi:10.1053/rvsc.2000.0419

[57] C. L. Barbieri, "Immunology of Canine Leishmaniasis," Parasite Immunology, Vol. 28, No. 7, 2006, pp. 329-337. doi:10.1111/j.1365-3024.2006.00840.x

[58] A. B. Reis, O. A. Martins-Filho, A. Teixeira-Carvalho, M. G. Carvalho, W. Mayrink, J. C. França-Silva, R. C. Giunchetti, O. Genaro and R. Corrêa-Oliveira, "Parasite Density and Impaired Biochemical/Hematological Status Are Associated with Severe Clinical Aspects of Canine Visceral Leishmaniasis," Research in Veterinary Science, Vol. 81, No. 1, 2006, pp. 68-75. doi:10.1016/j.rvsc.2005.09.011

[59] G. M. Santos-Gomes, R. Rosa, C. Leandro, S. Cortes, P. Romão and H. Silveira, "Cytokine Expression During the Outcome of Canine Experimental Infection by Leishmania infantum," Veterinary Immunology and Immunopathology, Vol. 88, No. 1-2, 2002, pp. 21-30. doi:10.1016/S0165-2427(02)00134-4

[60] E. Carrillo, S. Ahmed, K. Goldsmith-Pestana, J. Nieto, Y. Osorio, B. Travi, J. Moreno and D. McMahon-Pratt, "Immunogenicity of the P-8 Amastigote Antigen in the Experimental Model of Canine Visceral Leishmaniasis," Vaccine, Vol. 25, No. 8, 2007, pp. 1534-1543. doi:10.1016/j.vaccine.2006.10.036

[61] I. F. Amorim, S. M. Silva, M. M. Figueiredo, E. P. Moura, R. S. Castro, T. K. Lima, N. F. Gontijo, M. S. Michalick, K. J. Gollob and W. L. Tafuri, "Toll Receptors Type-2 and CR3 Expression of Canine Monocytes and Its Correlation with Immunohistochemistry and Xenodiagnosis in Visceral Leishmaniasis," PLoS ONE, Vol. 6, No.11, 2011, doi:10.1371/journal.pone.0027679

[62] M. A. Sanchez, N. L. Diaz, O. Zerpa, E. Negron, J. Convit and F. J. Tapia, "Organ-Specific Immunity in Canine Visceral Leishmaniasis: Analysis of Symptomatic and Asymptomatic Dogs Naturally Infected with Leishmania chagasi," The American Journal of Tropical Medicine and Hygiene, Vol. 70, No. 6, 2004, pp. 618-624.

[63] L. M. Deane, "Observações sobre a Transmissão da Leishmaniose Visceral no Ceará," O Hospital, Vol. 47, 1955 , pp. $75-87$.
[64] B. L. Travi, C. J. Tabares, H. Cadena, C. Ferro and Y. Osorio, "Canine Visceral Leishmaniasis in Colombia: Relationship between Clinical and Parasitological Status and Infectivity for Sand Flies," The American Journal of Tropical Medicine and Hygiene, Vol. 64, No. 3-4, 2001, pp. 119-124.

[65] S. C. Xavier, I. M. Chiarelli, W. G. Lima, R. Gonçalves and W. L. Tafuri, "Canine Visceral Leishmaiasis: A Remarkable Histopathological Picture of One Asymptomatic Animal Reported from Belo Horizonte, Minas Gerais, Brazil," Arquivos Brasileiros de Medicina Veterinária e Zootecnia, Vol. 58, No. 6, 2006, pp. 994-1000. doi:10.1590/S0102-09352006000600004

[66] F.A. Melo, “Alterações da Matriz Extracelular na Pele de Cães com Leishmaniose Visceral Naturalmente Infectados," Ph.D. Dissertação, Universidade Federal de Viçosa, Minas Gerias, 2005.

[67] L. Solano-Gallego, H. Fernández-Bellon, P. Morell, D. Fondevila, J. Alberola, A. Ramis and L. Ferrer, "Histological and Immunohistochemical Study of Clinically Normal Skin of Leishmania infantum-Infected Dogs," Journal of Comparative Pathology, Vol. 130, No. 1, 2004, pp. 7-12. doi:10.1016/S0021-9975(03)00063-X

[68] E. P. Moura, R. R. Ribeiro, W. M. Sampaio, W. G. Lima, C. F. Alves, F. A. Melo, M. N. Melo, W. L. Tafuri, W. L. Tafuri and M. S. M. Michalick, "Histopathological and Parasitological Analysis of Skin Biopsies Tissues from Two Distinct Anatomical Areas of the Ears of Dogs Naturally Infected with Leishmania (Leishmania) chagasi," Brazilian Journal of Veterinary Pathology, Vol. 1, No. 1, 2008, pp. 10-15.

[69] R. C. Giunchetti, W. Mayrink, O. Genaro, C. M. Carneiro, R. Corrêa-Oliveira, O. A. Martins-Filho, M. J. Marques, W. L. Tafuri and A. B. Reis, "Relationship between Canine Visceral Leishmaniosis and the Leishmania (Leishmania) chagasi Burden in Dermal Inflammatory Foci," Journal of Comparative Pathology, Vol. 135, No. 2-3, 2006, pp. 100-107. doi:10.1016/j.jcpa.2006.06.005

[70] J. Hervás Rodríguez, E. Mozos, A. Méndez, J. Pérez and J. C. Gómez-Villamandos, "Leishmania Infection of Canine Skin fibroblasts in Vivo," Veterinary Pathology, Vol. 33, No. 4, 1996, pp. 469-473. doi: $10.1177 / 030098589603300423$

[71] C. Bogdan, N. Donhauser, R. Döring, M. Röllinghoff, A. Diefenbach and M. G. Rittig, "Fibroblasts as Host Cells in Latent Leishmaniosis," The Journal of Experimental Medicine, Vol. 191, No. 12, 2000, pp. 2121-2130. doi:10.1084/jem.191.12.2121

[72] D. Fondevila, M. Vilafranca and L. Ferrer, "Epidermal Immunocompetence in Canine Leishmaniasis," Veterinary Immunology and Immunopathology, Vol. 56, No. 3-4, 1997, pp. 319-327. doi:10.1016/S0165-2427(96)05755-8

[73] F. A. Melo, E. P. Moura, R. R. Ribeiro, C. F. Alves, M. V. Caliari, W. L. Tafuri, K. S. Calabrese and W. L. Tafuri, "Hepatic Extracellular Matrix Alterations in Dogs Naturally Infected with Leishmania (Leishmania) chagasi," International Journal of Experimental Pathology, Vol. 90, No. 5, 2009, pp. 538-548. doi:10.1111/j.1365-2613.2009.00681.x 
[74] J. Alvar, C. Cañavate, R. Molina, J. Moreno and J. Nieto, "Canine Leishmaniasis," Advances in Parasitology, Vol. 57, 2004, pp. 1-88. doi:10.1016/S0065-308X(04)57001-X

[75] L. M. Deane and M. P. Deane, "Visceral Leishmaniasis in Brazil: Geographical Distribution and Transmission," Revista do Instituto de Medicina Tropical de São Paulo, Vol. 4, No. 3, 1962, pp. 198-212.

[76] E. M. Michalsky, M. F. Rocha, A. C. da Rocha Lima, J. C. França-Silva, M. Q. Pires, F. S. Oliveira, R. S. Pacheco, S. L. dos Santos, R. A. Barata, A. J. Romanha, C. L. FortesDias and E. S. Dias, "Infectivity of Seropositive Dogs, Showing Different Clinical Forms of Leishmaniasis, to Lutzomyia Longipalpis Phlebotomine Sand Flies," Veterinary Parasitology, Vol. 147, No. 1-2, 2007, pp. 67-76. doi:10.1016/j.vetpar.2007.03.004

[77] R. Molina, C. Amela, J. Nieto, M. San-Andrés, F. González, J. A. Castillo, J. Lucientes and J. Alvar, "Infectivity of Dogs Naturally Infected with Leishmania infantum to Colonized Phlebotomus perniciosus," Transactions of the Royal Society of Tropical Medicine and Hygiene, Vol. 88, No. 4, 1994, pp. 491-493. doi:10.1016/0035-9203(94)90446-4

[78] M. A. Almeida, E. E. Jesus, M. L. Sousa-Atta, L. C. Alves, M. E. Berne and A. M. Atta, "Clinical and Serological Aspects of Visceral Leishmaniasis in Northeast Brazilian Dogs Naturally Infected with Leishmania chagasi," Veterinary Parasitology, Vol. 127, No. 3-4, 2005, pp. 227-232. doi:10.1016/j.vetpar.2004.10.010

[79] C. C. Santana, J. Vassallo, L. A. R. de Freitas, G. G. S. Oliveira, L. C. Pontes-de-Carvalho and W. L. C. DosSantos, "Inflammation and Structural Changes of Splenic Lymphoid Tissue in Visceral Leishmaniasis: A Study on Naturally Infected Dogs," Parasite Immunology, Vol. 30, No. 10, 2008, pp. 515-524. doi:10.1111/j.1365-3024.2008.01051.X

[80] W. G. Lima, P. S. Oliveira, M. V. Caliari, R. Gonçalves, M. S. Michalick, M. N. Melo, W. L. Tafuri and W. L. Tafuri, "Histopathological and Immunohistochemical Study of Type 3 Complement Receptors (CD11b/CD18) in Livers and Spleens of Asymptomatic and Symptomatic Dogs Naturally Infected with Leishmania (Leishmania) chagasi," Veterinary Immunology and Immunopathology, Vol. 117, No. 1-2, 2007, pp.129-136. doi:10.1016/j.vetimm.2007.02.012

[81] J. S. Silva, A. C. Andrade, C. C. Santana, L. Q. Santos, C. I. Oliveira, P. S. T. Veras, J. Vassallo and W. L. C. dos-Santos, "Low CXCL13 Expression, Splenic Lymphoid Tissue Atrophy and Germinal Center Disruption in Severe Canine Visceral Leishmaniasis," PLoS ONE, Vol. 7, No. 1, 2012, pp. 1-10. doi:10.1371/journal.pone.0029103

[82] R. C. Giunchetti, O. A. Martins-Filho, C. M. Carneiro, W. Mayrink, M. J. Marques, W. L. Tafuri, R. Corrêa-Oliveira and A. B. Reis, "Histopathology, Parasite Density and Cell Phenotypes of the Popliteal Lymph Node in Canine Visceral Leishmaniasis," Veterinary Immunology and Immunopathology, Vol. 121, No. 1-2, 2008, pp. 23-33. doi:10.1016/j.vetimm.2007.07.009
[83] L. Beattie, A. Peltan, A. Maroof, A. Kirby, N. Brown, M. Coles, D. F. Smith and P. M. Kaye, "Dynamic Imaging of Experimental Leishmania Donovani-Induced Hepatic Granulomas Detects Kupffer Cell-Restricted Antigen Presentation to Antigen-Specific CD8+ T Cells," PLoS Pathogens, Vol. 6, No. 3, 2010, Article ID e1000805. doi:10.1371/journal.ppat.1000805

[84] W. G. Lima, M. S. Michalick, M. N. de Melo, W. L. Tafuri and W. L. Tafuri, "Canine Visceral Leishmaniasis: A Histopathological Study of Lymph Nodes," Acta Tropica, Vol. 92, No. 1, 2004, pp. 43-53. doi:10.1016/j.actatropica.2004.04.007

[85] R. C. Giunchetti, W. Mayrink, C. M. Carneiro, R. Corrêa-Oliveira, O. A. Martins-Filho, M. J. Marques, W. L. Tafuri and A. B. Reis, "Histopathological and Immunohistochemical Investigations of the Hepatic Compartment Associated with Parasitism and Serum Biochemical Changes in Canine Visceral Leishmaniasis," Research in Veterinary Science, Vol. 84, No. 2, 2008, pp. 269-77. doi:10.1016/j.rvsc.2007.04.020

[86] F. A. Costa, H. Goto, L. C. Saldanha, S. M. Silva, I. L. Sinhorini, T. C. Silva and J. L. Guerra, "Histopathologic Patterns of Nephropathy in Naturally Acquired Canine Visceral Leishmaniasis," Veterinary Pathology, Vol. 40, No. 6, 2003, pp. 677-684. doi:10.1354/vp.40-6-677

[87] A. Jain, M. Berthwal, V. Tiwari and S. C. Maitra, "Immune Complex Mediated Lesions in Experimental Kala Azar: An Ultrastructural Study," Indian Journal of Pathology \& Microbiology, Vol. 43, No. 1, 2000, pp. 13-16.

[88] F. A. Costa, M. G. Prianti, T. C. Silva, S. M. Silva, J. L. Guerra and H. Goto, "T Cells, Adhesion Molecules and Modulation of Apoptosis in Visceral Leishmaniasis Glomerulonephritis," BMC Infectious Diseases, Vol. 10, No. 112, 2010, pp. 1-12. http://www.biomedcentral.com/1471-2334/10/112.

[89] A. B. Reis, O. A. Martins-Filho, A. Teixeira-Carvalho, R. C. Giunchetti, C. M. Carneiro, W. Mayrink, W. L. Tafuri and R. Corrêa-Oliveira, "Systemic and Compartmentalized Immune Response in Canine Visceral Leishmaniasis," Veterinary Immunology and Immunopathology, Vol. 28, No. 1-3, 2009, pp. 87-95. doi:10.1016/j.vetimm.2008.10.307

[90] W. G. Couser, "Pathogenesis of Glomerular Damage in Glomerulonephritis," Nephrology, Dialysis, Transplantation, Vol. 13, Suppl 1, 1998, pp. 10-15. doi:10.1093/ndt/13.suppl 1.10

[91] R. J. Quinnell, L. J. Kennedy, A. Barnes, O. Courtenay, C. Dye, L. M. Garcez, M. A. Shaw, S. D. Carter, W. Thomson and W. E. Ollier, "Susceptibility to Visceral Leishmaniasis in the Domestic Dog Is Associated with MHC Class II Polymorphism," Immunogenetic, Vol. 55, No. 1, 2003, pp. 23-28.

[92] L. Altet, O. Francino, L. Solano-Gallego, C. Renier and A. Sánchez, "Mapping and Sequencing of the Canine NRAMP1 Gene and Identification of Mutations in Leishmaniasis-Susceptible Dogs," Infection and Immunity, Vol. 70, No. 6, 2002, pp. 2763-2771. doi:10.1128/IAI.70.6.2763-2771.2002 